How do development HR practices contribute to employees' motivation to continue working beyond early retirement age?

\author{
Tuğba Polat \\ VU University Amsterdam, the Netherlands \\ P. Matthijs Bal \\ University of Lincoln, United Kingdom \\ Paul G.W. Jansen \\ VU University Amsterdam, the Netherlands
}

Correspondence should be addressed to: Matthijs Bal, University of Lincoln, Lincoln

International Business School, Lincoln LN6 7TS, United Kingdom. Email: mbal@lincoln.ac.uk.

This manuscript has been accepted for publication in Work, Aging and Retirement. 


\title{
How do development HR practices contribute to employees' motivation to continue working beyond early retirement age?
}

\begin{abstract}
This study tested a mediated model explaining two mechanisms through which perceived availability of developmental Human Resource (HR) practices are related to employee's motivation to continue working beyond early retirement. On the one hand, development HR relates to more perceptions of a positive development climate, and on the other hand, development HR fulfills the individual needs of workers to build a positive psychological contract with their organization. It was expected that development HR would be positively related to older employees' motivation to continue working. We further expected that these relationships would be mediated through perceptions of development climate, psychological contract fulfillment, organizational commitment, and work engagement. Hypotheses were tested using two samples $(N=313$ and $N=352)$ of employees working in health care organizations in the Netherlands, and largely supported the hypotheses, finding significant indirect effects of development HR to motivation to continue working. The results of this study demonstrate not only that development HR may be important for older workers to be motivated to continue working, but also show how these relationships manifest.
\end{abstract}

Keywords: Continuing working, retirement, development HR practices, organizational climate, psychological contract, organizational commitment, work engagement

RUNNING HEAD: DEVELOPMENT HR AND CONTINUING WORKING 
Populations in many countries worldwide are aging due to both increasing life expectancy and decreasing birthrates (European Commission, 2014; U.S. Census Bureau, 2016). These demographic developments put pressure on labor markets as an increasing number of workers are about to retire in the next decade(-s). It is therefore important that organizations anticipate these changes, and understand the factors that may facilitate prolonged careers of workers in a healthy and engaged manner (European Commission, 2011). The relevant question for many organizations is how they can encourage older workers to continue working beyond their (early) retirement age. While countries are increasingly abolishing official retirement ages, many workers are still able to retire early, through retirement packages and early-retirement programs (Fasbender, Wang, Voltmer, \& Deller, 2016). It is therefore needed to investigate the factors that relate to employee motivation to continue working beyond their early retirement. The focus of this study, therefore, is on the predictors of motivation to continue working beyond early retirement age.

Many factors (individual, job and organizational, family, and socioeconomic) may influence an employee's decision to retire or to continue working (Wang \& Shultz, 2010), but an employer's power to influence many of these factors may be limited (e.g., family situation or socioeconomic factors). The focus of this study is on the factors under control of organizations, as they are able to invest and have discretion over these factors. Over the last decades, many studies have been conducted on the factors that lead people to continue working beyond their retirement age. For instance, Fasbender et al. (2016) found that employee reasons to engage in post-retirement work resulted from needs for social contacts as well as personal satisfaction. Furunes and colleagues (2015) found that older workers wanted new challenging tasks, and also benefitted from a more personalized approach (Bal et al. 2012). However, other factors also affect motivation to continue working (e.g., Kalokerinos, Von Hippel, \& Henry, 2015; Moen, Kojola, Kelly, \& Karakaya, 2016). For instance, research has shown that decreases in burnout 
over time may enhance the expectation of being employed at pension age (Moen et al., 2016). Hence, employee well-being is important as well. Moreover, organizations also invest in their team composition to foster knowledge retention, as employees with the right skills are better able to continue working (Burmeister \& Deller, 2016). Yet, beyond well-being and skills (i.e., being able to continue working), employees also need the motivation to continue working. Several studies have found, for example, that organizational commitment and organizational support are positively related to the decision to prolong work participation (Armstrong-Stassen \& Ursel, 2009; Bal \& Visser, 2011; Gobeski \& Beehr, 2009; Kalokerinos et al., 2015).

Moreover, studies have investigated relationships between HR practices and older worker motivation (e.g., Armstrong-Stassen \& Schlosser, 2008; Gobeski \& Beehr, 2009; Kooij et al., 2013; Schopman, Kalshoven, \& Boon, 2015), showing that HR practices may contribute to older workers' motivation to continue working. However, there is currently little known about how HR practices relate to higher motivation, and thus which processes underpin these relationships. On the one hand, it has been shown that HR practices that involve employee development contribute to the retention of older workers (Bal, de Jong, Jansen, \& Bakker, 2012; Furunes et al., 2015). Offering development HR practices signals the organization's commitment toward its employees and creates perceptions of a positive development climate. In particular, perceptions of available development practices may relate to a perceived climate in which employees are stimulated to develop themselves (Bal et al., 2012). On the other hand, an individual-oriented process predicts that development practices create a strong positive psychological contract between the employee and the organization through which motivation is enhanced.

Therefore, the current study investigates how employees' perceived availability of developmental HR practices (henceforth development HR) relates to motivation to continue working, as well as the mediating mechanisms in this relationship (i.e., perceptions of 
development climate and psychological contract). In so doing, we study older employees' retirement decisions from an HRM perspective (Wang \& Shultz, 2010), and in particular how organizations may implement HR practices such that older workers are motivated to continue working. Through investigation of two mechanisms, we are able to assess which mechanisms explain the relationships between development HR and motivation to continue working. The study focuses on relationships of development HR with motivation to continue working beyond early retirement age, as currently, still many workers are able to retire before the age of 65 , and hence, for organizations it is also important to facilitate workers to postpone early retirement (Bal et al., 2012). Moreover, as a lack of motivation to continue working indicates an unwillingness to continue working, it is also important for organizations to assess those motivations well before the actual retirement age, as it may provide important clues as to the interventions that could be designed by HR-practitioners to enhance these motivations.

Moreover, it is well established that intentions are strong predictors of actual behaviors (given a supportive context; Bal et al., 2012), and hence motivation to continue working is important both theoretically and practically.

This paper discusses the results of two samples from the Netherlands, in which the mediated relationships are tested between development HR and motivation to continue working. Employees from two health care organizations participated in the study which focused on investigation of means through which organizations could enhance motivation to continue working among their employees. Through means of two samples the results can be crossvalidated, thereby contributing to greater robustness of the findings from the study.

\section{Theory and Hypotheses}

The Role of Perceived Human Resource (HR) practices in Motivation to Continue Working

The HRM literature advocates that HR practices are key communicators for the organization and may have a substantial impact on organizational outcomes (Guest \& Conway, 
2002; Paauwe, 2009). Empirical studies by, for example, Bal and colleagues (2012) and Armstrong-Stassen and Schlosser (2008) have demonstrated that organizations indeed can influence retirement intentions through their HR practices. However, research has also shown that in general, employers are reluctant to invest in older workers (e.g., Bal \& Jansen, 2016; Van Dalen, Henkens, \& Wang, 2015), and that older workers themselves may hesitate to participate in development and training. Several studies have found that organizations tend to invest less in their older workers than in younger members of the workforce (Blundell, Dearden, Meghir, \& Sianesi, 1999; Maurer \& Rafuse, 2001; Taylor \& Walker, 1998). By doing so, organizations may make their older employees effectively (feel) redundant (Taylor \& Walker, 1998). In the context of a societal need to prolong working ages (e.g., Fasbender et al., 2016), it is important to understand not only the investments that are currently made by employers to engage their older workers and motivate them to continue working, but also how development may enable older workers to retain motivation as well as the processes through which development enhances their motivation. Hence, development may act as the instigator of the process that relates to higher motivation to continue working. In the current study, we postulate that especially employee perceptions of development HR being available are important in relation to motivation to continue working (Bal et al., 2012).

HR practices can contribute to the motivation to continue working in two ways. First, they can enable and therefore support employees to continue working by shaping their skills (Bowen \& Ostroff, 2004). If organizations invest in development HR for older workers, they provide them with means to be able to continue working (Bal, et al., 2012). Second, HR practices shape employee attitudes, such that perceptions of availability increase work motivation and commitment (Bowen \& Ostroff, 2004). Several studies have demonstrated that work motivation and commitment are positively related to workforce participation in older age (Gobeski \& Beehr, 2009; Kalokerinos et al., 2015; Shultz, et al., 1998). In this study, we focus 
in particular on the role of attitudes, and expect two theoretical processes through which attitudes mediate the relationships between development HR and motivation to continue working. Signaling theory (Ostroff \& Bowen, 2000) and social exchange theory (Blau, 1964; Eisenberger, Huntington, Hutchison, \& Sowa, 1986) provide different insights into how development HR is related to older workers' attitudes and motivation.

Signaling theory argues that HR practices create an organizational climate that collectively shapes employee attitudes at the team or organizational level. Thus, signaling theory provides an explanation of why development HR may relate to perceived development climate. HR practices signal what is expected from employees by shaping the organizational climate employees experience (Ostroff \& Bowen, 2000). In the context of extending working lives, offering HR practices that involve development especially represents organizational support as they show the organization's willingness to invest in its human capital and its commitment to older employees (Armstrong-Stassen \& Ursel, 2009; Bowen \& Ostroff, 2004). Overall, we therefore argue that when employees perceive their organizations offering development HR, it relates to more positive perceptions of development climate. Climate perceptions are a representation of the organization's internal environment, which results from the behavior of organizational members, including supervisors (González-Romá, FortesFerreira, \& Peiró, 2009; James \& Jones, 1974). Supervisors form an integrative part of climate perceptions about older workers, for instance through supporting older workers in their development, or withholding resources to older workers (Chiu, Chan, Snape, \& Redman, 2001; Kozlowski \& Doherty, 1989). Hence, the first hypothesis is:

Hypothesis 1: Availability of development HR practices is positively related to a perceived development climate for older workers.

Signaling theory further argues that, when employees perceive development HR to be available, this boosts their perceptions of being valued by the organization, and being part of a 
benevolent organization where people are valued cared for (Blau, 1964). This entails individual's perceptions of a development climate in the organization consisting of a sense of meaning and belongingness for people as part of organizations, which is fundamental to their relationship with the organization. This may lead employees to be more inclined to develop commitment toward the organization and thereby to work harder in pursuit of organizational goals (Blau, 1964; Eisenberger, et al., 1986). Studies that examined the relationship between positive work attitudes, such as organizational commitment, and work outcomes, have consistently found that organizational commitment is negatively related to turnover intention (Allen, Shore, \& Griffeth, 2003; Meyer \& Smith, 2000), and positively related to intention to remain (Armstrong-Stassen \& Schlosser, 2008) and to the motivation to work in older age (Gobeski \& Beehr, 2009). We thus expect that when older employees experience an development climate that encourage older workers to develop themselves, their feelings of organizational commitment will be higher.

Similarly, development climate has also been found to be positively related to work engagement. The job-demands and resources model (Bakker, Hakanen, Demerouti, \& Xanthopoulou, 2007) suggests that an organization's climate can serve as a job resource that leads to work engagement (Schaufeli \& Bakker, 2004). Thus, individual experiences of a development climate relates to higher work engagement through employees' sense that they are in possession and control over important resources in their work. Particularly in the context of continuing to work beyond retirement, perceptions of a climate in which older workers' development is supported will relate to positive work attitudes. Given the above, we formulate the following hypotheses:

Hypothesis 2: A perceived developmental climate for older workers is positively related to (a) organizational commitment and $(b)$ work engagement. 
While signaling theory predicts a climate-oriented process through which development relates to higher motivation to continue working, social exchange theory predicts how development practices relate to older workers' individual experiences of their relationship with the organization (Blau, 1964; Eisenberger et al., 1986). More specifically, HR practices shape an employee's psychological contract with the employer (Guest \& Conway, 2002; Ostroff \& Bowen, 2000). A psychological contract is defined by Rousseau (1995, p.9) as "individual beliefs, shaped by the organization, regarding terms of exchange agreement between individuals and their organization". Psychological contracts are shaped through the explicit and implicit obligations of the organization to its employees (Rousseau, 1995). These obligations are relevant for employees, as based on their perceptions of fulfillment of these obligations employees commit themselves to their organizations (Rousseau, 1995). HR practices are relevant in the context of the psychological contract, as perceived availability of HR practices indicates a willingness of the organization to fulfill the psychological contract with the employee. The more employees perceive development practices to be available, the more positively they evaluate their psychological contract (Taylor \& Walker, 1998). Hence, a psychological contract perspective on HR practices explains how older workers may develop stronger individual ties with their organization as a result of available development practices, as it shows that the organization is fulfilling their part of the deal. Our third hypothesis is:

Hypothesis 3: Availability of development HR practices is positively related to perceived psychological contract fulfillment.

Many studies have found that individuals experiencing fulfillment of their psychological contract display positive work attitudes, such as high organizational commitment and work engagement (Zhao, Wayne, Glibkowski, \& Bravo, 2007). Social exchange theory shows that when a psychological contract is perceived to be fulfilled, an employee is likely to feel obligated to reciprocate the benevolent treatment by the employer through committing to the 
organization and by becoming more engaged in the job (Zhao et al., 2007). Therefore, we expect that a perception of psychological contract fulfillment will be related to positive work attitudes such as organizational commitment and work engagement. As a result, the following hypothesis can be formulated:

Hypothesis 4: Psychological contract fulfillment is positively related to older workers' (a) organizational commitment and (b) work engagement.

\section{Positive work attitudes and the motivation to work beyond retirement age}

Employee attitudes about their organizations have been investigated previously in terms of their effect on retirement behavior. Typically, studies have shown that employees with positive work-related attitudes, such as organizational commitment and work engagement, participate longer in the workforce (Adams, Prescher, Beehr, \& Lepisto, 2002; ArmstrongStassen \& Schlosser, 2008; Gobeski \& Beehr, 2009; Kalokerinos et al., 2015; Taylor \& Shore, 1995). This relationship can be explained through the work-role attachment theory of adjusting to change (such as those resulting from retirement; Carter \& Cook, 1995). If work roles are important for an individual, leaving those roles is likely to create dissatisfaction (Shultz, et al., 1998). Hence, individuals with a strong identification with the organization are more likely to continue working (Kim \& Feldman, 2000). Similarly, individuals who have high levels of work engagement, or a strong identification with their work role, will also have a stronger motivation to continue working (Bal et al., 2012). The fifth and the sixth hypotheses are therefore formulated as follows:

Hypothesis 5: Organizational commitment is positively related to older workers' motivation to work beyond retirement age.

Hypothesis 6: Work engagement is positively related to older workers' motivation to work beyond retirement age. 
The combined set of hypotheses implies a double sequential mediation effect, with development HR relating to motivation to continue working via development climate on the one hand, and psychological contract fulfillment on the other hand. Affective commitment and work engagement mediate these relationships as well, leading to the model shown in Figure 1.

Insert Figure 1 about here

\section{Method}

\section{Samples and Procedure}

The study was conducted in 2009 in the Netherlands. At that time, the topic of postponing retirement was receiving considerable public attention as the government had disclosed plans to increase the pension age. Data for this study were collected from two adult care organizations. The mean actual retirement age in the health sector at the time the data were collected was 62.1 (Statistics Netherlands, 2012). The data from the first care organization (Sample 1) were used to test the model, and the second set (Sample 2) was employed to validate the model. Employees were approached through their supervisors to complete a questionnaire. Response could be provided hard copy or digitally. Our study formed part of a larger research project and only respondents who were aged 40 and older were included in the analyses. First, there is no theoretical indication of when workers start to think about and prepare for their retirement (Kooij, de Lange, Jansen, \& Dikkers, 2008). Hence, we decided to capture a rather broad range of employees, but it was also decided to leave out workers below 40, as retirement for younger workers is a relative distinct concept, and generally they are not engaged in retirement planning yet (Lusardi \& Mitchell, 2009). Moreover, 40 was also chosen in the context of the current study, as in health care, many workers (e.g., nurses, nurse practitioners) start at a relative young age (around 20), and due to the physically demanding nature of the 
work, from around the age of 40, many workers tend to have complaints and difficulties with respect to the demands of their work. As a result, many express an interest in developing themselves, or are forced to engage in development to enrich their work or to conduct different work, and thus be able to stay employable (in or outside their organization).

Sample 1 consisted of employees of an adult care institution that provides medical care. The overall response rate was $49 \%$, and of these $55.7 \%$ matched our age criterion (giving a sample size for our purposes of $N=313$ ). The average age of the respondents in our sample was 49.78 years ( $S D=5.63$, age range: $40-63$ years). The vast majority of the respondents in this study were female $(91.7 \%)$, which is not uncommon for this sector. The average organizational tenure was 11.19 years $(S D=8.45)$. Among the respondents, $85.4 \%$ were married or were in a registered partnership (of whom 50\% also had children living at home). In terms of education, $10.1 \%$ indicated primary education as their highest completed education level; $38 \%$ secondary education; $10.4 \%$ higher secondary education; $34.9 \%$ intermediate vocational training; and $6.6 \%$ university.

Sample 2 consisted of employees of an adult day care institution that provides nonmedical care. The overall response rate was 50\%. As with the first sample, only respondents aged 40 and over (64.8\% of all respondents) were included in our analyses, giving a sample size of 352. Again, the vast majority of the respondents in our sample were female $(87.7 \%)$. The mean age of the respondents was 50.04 years $(S D=5.26$, age range: $40-63$ years), the respondents had a mean organizational tenure of 11.96 years $(S D=9.52)$. Among the respondents, $87.4 \%$ were married or had a registered partnership (of whom $48.5 \%$ also had children living at home). In educational terms, $7.1 \%$ had completed no more than primary education; 39.8\% secondary education; $12.6 \%$ higher secondary education; $36 \%$ intermediate vocational training; and $4.5 \%$ university.

\section{Measures}


Existing validated scales were used to measure the constructs. Unless otherwise stated, the questions sought responses on a five-point scale $(1=$ strongly disagree to $5=$ strongly agree). Appendix A presents a full list of items used in this study. Availability of developmental HR practices was measured by asking respondents about the extent to which four selected developmental HR practices were available within their organization. The HR practices selected were based on scales which were developed at the time of the study by other researchers, and which were published shortly after (Kooij, 2010; Kooij, Jansen, Dikkers, \& De Lange, 2014) and covered career planning, on-the-job development, promotion, and regular training. Respondents were asked the extent to which these HR practices were available to them. The reliability of the scale was .87 using Sample 1 and .86 for Sample 2. With regard to development activities, the questionnaire also included open questions asking what kind of training activities employees were involved in. Training activities included computer training, training for lifting, first aid training, training to cope with patient aggression, mentoring/ supervising training and management training among others.

Perceived development climate for older workers was measured with six items, again developed by Kooij (2010). The scale was based on previous research on supportive climates, which may result from both supervisor and organization (Tracey \& Tews, 2005; Dikkers et al., 2004). Items assess the support offered by organizations to older workers to use their skills and knowledge, and to develop themselves professionally. Theoretically, a development climate for older workers not only aims at skill development, but also to enable workers to use their experience and existing skills. This may not be directly related to their own learning, but is crucial for other workers in teams and departments, and as such when utilized may enhance the general learning within a unit, as older workers may share their experience and knowledge within the team (Burmeister \& Deller, 2016). In effect, the variable measures individual perceptions of the development climate. The reliability of the six-item scale was .90 using the 
first sample and .86 with the second sample. Exploratory factor analysis on the six items produced a single dimension for all items in each sample, and hence it was deemed appropriate to continue the analyses with the 6-item measure.

Psychological contract fulfillment was measured using the five-item psychological contract breach scale developed by Robinson and Morrison (2000). The items assess the extent to which employees felt that their organization had met its promises to the employee. The items were re-coded to measure fulfillment. The reliability of the scale was .86 for Sample 1 and .84 for Sample 2. Organizational commitment was measured by the eight-item affective organizational commitment scale of Allen and Meyer (1990). The reliability of the scale was .89 for Sample 1 and .85 for Sample 2. Work engagement was measured using six items taken from the Utrecht Work Engagement Scale (Schaufeli \& Bakker, 2003). From the original scale, three items measuring vigor and three items measuring dedication were selected. Due to the constraints in survey length, we decided to focus on the two core dimensions of work engagement. This choice was bolstered by empirical work of González-Romá, Schaufeli, Bakker and Lloret (2006), who argued and showed empirically that vigor and dedication could be perceived as the core dimensions of work engagement (see also Demerouti, Mostert, \& Bakker, 2010). Moreover, pilot tests were conducted among a group of workers, and employees within the HR-department. The outcomes of their experiences of filling out the survey were discussed in meetings prior to the launch of the survey. A consistent hesitation was found among the pilot tested employees about the meaning of the absorption-items in the Work Engagement measure (e.g., 'I get carried away when I'm working'), many of them indicating that these items did not reflect their work experiences. Hence, it was decided to remove these items of the engagement measure and to retain only the vigor and dedication dimensions, as they were perceived to have more content validity than the ambiguous absorption-items 
(Demerouti et al., 2010). Respondents were asked to respond on a seven-point scale ranging from 'never' to 'daily'. The reliability the scale was .93 for Sample 1 and .90 for Sample 2.

Motivation to continue working was measured using the three-item scale by ArmstrongStassen and Schlosser (2008), supplemented with an additional item. While the original scale measured 'motivation to remain', for this study the scale was adapted to measure the motivation to continuing working after the age at which workers in health care are able to retire in the Netherlands (which is 62 years). In the sector, this is referred to as the 'flexpension age', which was the term used in our current measure. Many workers were aware of this option and regarded 62 as the expected retirement age. This flexpension meant that workers could retire at the age of 62 while retaining $70 \%$ of their income at the age of retirement until the age of 65 (after which normal pension and state pension were guaranteed). This flexpension entitlement changed in 2014 due to changed government regulation, with various arrangements still being possible (for people born before 1950). However, at the time of the study, there was no clarity regarding the proposed changes. Currently, people's retirement age can differ based on their current age (between the age of 62 and 67), and willingness to undergo significant reductions in salary when they retire earlier.

Prior to the questions, there was a short explanatory paragraph outlining that prolonging one's working life was of topical interest in politics, and for unions and organizations, and that the following questions were related to this. The reliability of the scale was .96 for Sample 1 and .97 for Sample 2. Across the two samples there were five respondents in total who were 62 or 63 years old. Despite this small group of people having reached the flexpension age, the items still applied to them, as they aimed at measuring the extent to which they were motivated to continue working, and for how long they expected to continue working (e.g., "I expect to continue working as long as possible after my flex-pension age”). Hence, the items were still applicable to them even though they actually had made a decision to continue working after the 
eligible flexpension age. This approach is consistent with previous research, which has also investigated this construct among workers at higher ages (up until 70 years; Armstrong-Stassen \& Schlosser, 2008).

\section{Control variables}

In the analyses, we controlled for the effects of age, gender, subjective health, education, sector experience, training participation, the importance of finances in retirement decisions, and the importance of the expectations of a partner in the retirement decision since earlier studies had found that these variables were related to retirement decisions (Kooij et al., 2008; Luchak, et al., 2008; Talaga \& Beehr, 1995; Wang, et al., 2008). We specifically controlled for employee skills through measures of education, sector experience, and participation in training, as they may contribute to employee skills to be able to continue working (Kooij et al., 2008). Age and gender were measured by asking respondents directly for their year of birth (recoded to indicate someone's age $)$ and their gender $(1=$ male, $2=$ female $)$. Subjective health was measured by asking respondents how healthy they considered themselves in comparison with people of similar age $(1=$ much less healthy, $5=$ much healthier $)$. Education was measured using a 7-point scale measuring the highest educational degree $(1=$ primary school; $7=$ university degree). Sector experience was measured indicating the amount of years spent working in health care $(1=$ less than a year; $2=1-3$ years; $3=3-10$ years; $4=$ more than 10 years). Training participation was measured through asking whether respondents had attended a training during the previous year $(1=$ no; $2=$ yes $) .49 \%$ of the respondents in Sample 1 , and $52 \%$ in Sample 2, had participated in training during the previous year. We controlled for participation in training as in health care, workers are generally undertaking mandatory training to update their knowledge of procedures and rules. As these mandatory trainings are not directly aimed at development of the employee to be able to enhance motivation to continue working, we included participation in training as control in order to capture the true developmental 
aspects of development HR in relation to the outcomes beyond the more general effects that training participations may elicit. Financial importance was measured by asking respondents how important finances were in their decision to retire or continue working $(1=$ very unimportant, $5=$ very important). The expectation of a partner was measured by asking respondents how important the expectations of their partner about the age they should retire were in their decision when to retire $(1=$ very unimportant, $5=$ very important $)$. Analysis

To assess the factor structure of the six multi-item scales for each of the two samples, we conducted a confirmatory factor analysis (CFA) using MPlus (Muthen \& Muthen, 2012). Table 1 shows the results of the CFAs. We not only tested the proposed model but also alternative CFAs. The CFA results indicated a good fit for both samples using the postulated 6factor model (development HR, development climate, psychological contract fulfillment, organizational commitment, work engagement, and the motivation to continue working). The standardized coefficients of the factor loadings were significant and above .52 for Sample 1 and above .53 for Sample 2. Further, the model fit was significantly better than that of alternative models for both samples. In addition, we tested for common method variance by adding a common method factor to the CFA (Podsakoff, MacKenzie, Lee, \& Podsakoff, 2003) and the results did not suggest common method variance (see Table 1; 7-factor model).

\section{Insert Table 1}

The hypothesized model was tested using structural equation modeling, with MPlus (Muthen \& Muthen, 2012). We tested the postulated model for each sample using 1,000 bootstraps. Observed items were used as indicators of the latent variables. To test the hypothesized model, significance levels of the paths as well as the indirect and total effects 
were assessed; and to test the extent to which the model fitted the data, the RMSEA, SRMR, CFI, and TLI were assessed.

\section{Results}

\section{Descriptive Statistics}

Means, standard deviations, and the correlations among the variables being studied are presented in Table 2 for Sample 1, and Table 3 for Sample 2.

Insert Tables 2 and 3 about here

\section{Hypotheses Testing}

The model obtained acceptable fit for Sample $1(\chi 2=1886.12, d f=741, p<.001$, RMSEA $=.07$, SRMR $=.09, \mathrm{CFI}=.83, \mathrm{TLI}=.81)$. The model for Sample 2 obtained acceptable fit as well $(\chi 2=2067.54, d f=741, \mathrm{RMSEA}=.08, \mathrm{SRMR}=.09, \mathrm{CFI}=.82, \mathrm{TLI}=$ .80). Table 4 provides the unstandardized estimates for Sample 1, while Table 5 shows the results of the analyses for Sample 2.

Insert Tables 4 and 5 about here

The results of the study indicate positive and significant relationships between development HR and development climate (Table 4: Sample 1: $\mathrm{b}=.386, p<.001$; Table 5: Sample 2: $\mathrm{b}=.438, p<.001)$, which supports Hypothesis 1 . The results demonstrate that the perceived availability of development HR practices is related to higher organizational development climate for older workers. Furthermore, Hypothesis 2 is also supported by the results of the analyses showing positive relationships between organizational development climate for older workers and both organizational commitment (Sample 1: $\mathrm{b}=.198, p<.01$; 
Sample 2: $\mathrm{b}=.208, p<.001)$ and work engagement (Sample 1: $\mathrm{b}=.311, p<.01 ;$ Sample 2: $\mathrm{b}=$ $.316, p<.01)$. In addition, the results also support Hypothesis 3 by demonstrating a significant relationship between development HR and psychological contract fulfillment (Sample 1: $b=$ $.402, p<.001$; Sample 2: $\mathrm{b}=.385, p<.001)$. The relationships between psychological contract fulfillment and both organizational commitment (Sample 1: $\mathrm{b}=.296, p<.001 ;$ Sample 2: $\mathrm{b}=$ $.122, p<.05$ ) and work engagement were also significant (Sample 1: $\mathrm{b}=.225, \mathrm{p}<.01$; Sample $2: \mathrm{b}=.176, \mathrm{p}<.05)$, thus supporting Hypothesis 4. Further, the results demonstrate that organizational commitment (Sample 1: $\mathrm{b}=.283, p<.01 ;$ Sample 2: $\mathrm{b}=.243, n s$ ) was only related to motivation to continue working in Sample 1, but not in Sample 2. Work engagement (Sample 1: $\mathrm{b}=.153, p<.05 ;$ Sample $2: \mathrm{b}=.152, p<.05$ ) was positively related to the motivation to continue working in both samples. In all, these results partially support Hypothesis 5 and fully support hypothesis 6.

Moreover, we used bootstrapped indirect effects to estimate whether development HR contributed significantly to motivation to continue working. For Sample 1, the total indirect effect of development HR on motivation to continue working was significant $(b=.087, p<$ .01 ), and we found that the indirect effect of development HR on motivation to continue working was significantly mediated by psychological contract fulfillment and commitment $(b=$ $.034, p<.05$ ), presenting evidence that beyond the total effect of the combination of factors, it was psychological contract fulfilment and commitment that mediated the relationships. For Sample 2, the total indirect effect was also significant $(b=.065, p<.05)$, but none of the specific indirect effects were significant, although the indirect effect of development HR via development climate and engagement was in the expected direction $(b=.021, p<.10)$. Hence, it can be concluded that for Sample 2, it was the combination of mediators that explained the indirect relationships, rather than one specific indirect effect that explained the mediation between development HR and motivation to continue working. 
Post-Hoc Analyses

To further validate our results, we performed a number of post-hoc analyses to test whether the results would be stable under different conditions. First, we tested bootstrapped models without control variables to test whether relationships were stable. The results show for both samples that the significance levels of the relationships were not influenced by removing the control variables from the analyses (full results to be obtained from the first author). We conclude that the relationships under study are generally stable with and without the control variables. Moreover, we tested whether different constructions of the development climate measure would produce different results, as the existing measure was a combination of supervisor and organization-focused items, as well items with a developmental focus and a focus on utilizing skills. The results of these analyses show that across both samples, the use of either three items (focusing only on organizational-focused items of climate), or four items (leaving out the two 'utilizing skills' items) produced identical results, with development HR being positively related to all constructions of the climate measure, and the different climate measures being positively related to both commitment and engagement. Moreover, the indirect relationships were stable across the different models.

Finally, it was tested whether age moderated the relationships under study, as it might be that the relationships are stronger for younger or older workers (see e.g., Bal et al., 2008, for an empirical example). We tested models with age moderating the relationships between development HR and development climate and psychological contract fulfilment, and we also tested models for both samples with age moderating the relationships of development HR with all of the outcomes (all endogenous variables). In Sample 1, a significant interaction appeared between age and development HR in relation to development climate $(b=.022, p<.05)$. We found that the relationship of development HR with development climate was more strongly positive among older workers ( $1 \mathrm{SD}$ above the mean: $\mathrm{b}=.50, p<.001)$, while the relationship 
was less strongly positive among relatively younger workers (1SD below the mean: $\mathrm{b}=.25, p<$ $.01)$. None of the other interaction effects of age with development HR were significant. For Sample 2, none of the interaction effects were significant. Hence, this provides some evidence that development HR becomes even more important for older workers.

\section{Discussion}

The current study investigated how development HR practices related to employee motivation to continue working beyond early retirement. The results demonstrate that worker perceptions of development HR being available to them relates to higher motivation to continue working because their perception of the availability of these practices colors their perceptions of both the organizational climate and their psychological contract, both of which are related to work attitudes. In line with other studies (e.g., Gobeski \& Beehr, 2009), the results demonstrate that employees' attitudes toward work and specific jobs are related to their willingness to continue working. However, in the second sample, the relationship between organizational commitment and motivation to continue working was not significant, showing that it was in particular engagement which related to motivation to continue working. The indirect effects further showed that it was generally the combination of climate and psychological contract that explained the mediation effects, while there was some indication of a particular strong mediation of psychological contract and commitment in Sample 1.

The results of our analyses with both samples indicate that the perceived availability of developmental HR practices is related to a belief that the organization is providing a climate in which older employees can develop themselves and also that the psychological contract is being fulfilled. We have shown that two distinct processes explain the relationships of development practices with motivation to continue working. One the one hand, signaling theory (Ostroff \& Bowen, 2000) shows that HR practices may create a positive development climate, in which employees are stimulated to develop themselves so that they are enabled to have the right skills 
and abilities to continue working. As an organizational development climate is important to create a social atmosphere where older workers feel encouraged by their organization and supervisor to develop themselves, this represents a somewhat underestimated part of the quest to enhance older workers' motivation to extend their working lives. Previous research has shown that when older workers have development deals, but are unable to transfer these to the workplace due to an unsupportive environment, it may actually have no positive relationship with motivation to continue working (Bal et al., 2012). It is therefore crucial to understand how organizations may facilitate older workers in continuous learning, through taking an approach aimed at creating positive climates in teams and departments, rather than only focusing on individual workers.

In addition, we have shown that older workers' individual psychological contract may be enhanced as a result of available development practices, through which they are more highly motivated to continue working. Social exchange theory (Blau, 1964; Eisenberger, et al., 1986) argues that through development practices, a relationship between employee and organization is enforced, which creates a sense of reciprocity and boosts employees' commitment toward the organization. This study has found that in particular work engagement, generated by the perception of development HR practices being available, specifically contributes to motivation to continue working beyond early retirement. Thus, we show that motivation to continue working is higher through both perceptions about the collective and the individual; older workers not only have an individualistic motive to ensure the ability for continued employment, but also may take into account whether their immediate social environment is supportive, and thus whether there is a climate which stimulates them and others to keep developing.

The main contribution of the current paper is that this study investigated two mechanisms through which development HR may contribute to employee motivation to continue working. We have shown that generally, it is the total effect rather than the specific 
indirect effects that explained the relationship between development HR and motivation to continue working. Hence, it is important to stress that for development HR to have positive effects, both perceptions of climate (i.e., how one's organization thinks about development of older workers), and psychological contract (i.e., the strength of one's individual bond with the organization) need to be taken into account. Although existing studies often relate retirement behavior to work attitudes (e.g. Adams, et al., 2002; Gobeski \& Beehr, 2009), they tend to ignore that these work attitudes are formed and influenced by the organization's HR efforts. In addition, studies have not investigated the quality of the psychological contract in relation to retirement-related decisions. Our study demonstrates that psychological contract fulfillment relates to organizational commitment and subsequently motivation to continue working.

\section{Limitations and Suggestions for Further Research}

The first limitation of this study is that it is based on cross-sectional data, and thus the causality in the relationships found cannot be determined. A related limitation is that the data are from a single source. A useful direction for future research would therefore be to collect longitudinal data from multiple sources. The third limitation is that our sample was predominantly female. Although this limits the generalizability of the results, it could also be seen as an advantage. Demographic research demonstrates that women retire earlier than men (Eurostat, 2007) and research has found that there are gender differences in retirement behavior. For instance, research by Talaga and Beehr (1995) showed that a person's financial situation is an important factor in the retirement decision of men. From this perspective, men are often 'compelled' by their financial situation to continue working. Therefore, having a large female sample may be seen as an advantage since financial considerations often play less of a role in their retirement decision-making. Identifying the motivation of (primarily) women to continue working may also expose factors that apply to men but that have been dwarfed by financial issues in previous studies. Nevertheless, further research, with a more even distribution of men 
and women, is required to clarify this. The fourth limitation is concerned with the skewed distribution of respondents' education level (intermediate vocational training on average), the type of job (physically demanding), and the specific sector (adult care). It is therefore important to validate this study among respondents who are more evenly distributed in terms of educational level and types of jobs. However, for people with lower education and physically demanding jobs, it may be harder to continue working due to the physical burdens of work (e.g., Lund, Iversen, \& Poulsen, 2001; Pleau, 2010), and therefore, knowledge on the predictors of their motivation to continue working is even more important, as they may have accumulated fewer resources (e.g., human and social capital) than higher educated workers enabling them to find suitable employment beyond retirement.

The fifth limitation relates to the lack of an objective measure of development climate, as we relied solely on individual perceptions of collective representations of climate. For future research, it is important to take into account multiple perspectives in measuring climate within a unit (e.g., Bal et al., 2012). Moreover, it is also important to include a full measure of engagement for future research as we only used a shortened measure. In our study, we measured motivation to continue working, and did not test whether people actually continued working. Further, in our measurement of this variable, we did not make a distinction between continuing to work in the same organization as against in another organization. This is a limitation concerning the participating organizations, as there is insufficient information regarding the interventions they may design to retain skilled workers within their organizations. At the same time, it has a societal relevance, as for society in general it may be important that older workers remain active at higher ages, regardless of whether they remain in their organizations or contribute elsewhere. A direction for future research would be to measure actual post-retirement age behavior and be more specific as to what is meant by continuing to work, while differentiating between continue work within and outside the organization. Development is not 
solely a responsibility of organizations, as they may be unwilling or financially unable to invest in development (Van Dalen et al., 2009, 2015), but also of the worker, society and government, which have an important role to play in encouraging people to continuously develop themselves, such that they are able to contribute to society and to lead fulfilling lives (Bal \& Jansen, 2016; Moen et al., 2016), rather than to burnout at relatively low ages, through which they are less able to be active, healthy, and contributing to society.

While across many European countries state pensions have been more secure than in individualized countries such as the US and the UK, it is however, increasingly unstable. Consequently, a growing population of older people have higher financial necessity to continue working. Consequently, with a rising financial need to stay employed, it is important to understand the factors that contribute how they may enjoy their careers in later life. Hence, an important theoretical avenue concerns investigation of the types of work and jobs that are suitable to the needs of older workers, which increasingly vary as they age (Bal \& Jansen, 2015). Hence, an important question pertains to the steps that older workers take to ensure employability in later life, and how both organizations and governments facilitate this process. Thus, while we established the importance of development, future research could investigate more in terms of what kind of development, and how responsibilities emerge among workers, organizations, and society in encouraging development of workers and organizations.

\section{Conclusion}

The main conclusion of this research is that development HR practices are related to employees' motivation to continue working beyond early retirement. Organizations who are perceived to provide their employees with development HR practices are communicating that they want to invest in their employees, and this relates to positive attitudes and motivation. The results of this study demonstrate that this relationship is mediated by organizational climate, perceptions of the psychological contract, and work attitudes, and that development HR is 
important as it is related to both perceptions of a positive climate as well as perceptions of more psychological contract fulfillment of individual workers, which subsequently relate to more enjoyment of work and commitment to the organization. 


\section{References}

Adams, G. A., Prescher, J., Beehr, T. A., \& Lepisto, L. (2002). Applying work-role attachment theory to retirement decision-making. The International Journal of Aging and Human Development, 54, 125 - 137.

Allen, D. G., Shore, L. M., \& Griffeth, R. W. (2003). The role of perceived organizational support and supportive human resource practices in the turnover process. Journal of Management, 29(1), 99-118.

Allen, N. J., \& Meyer, J. P. (1990). The measurement and antecedents of affective, continuance and normative commitment to the organization. Journal of Occupational Psychology, 63, 1-18.

Armstrong-Stassen, M., \& Schlosser, F. (2008). Benefits of a supportive development climate for older workers. Journal of Managerial Psychology, 23(4), 419-437.

Bakker, A. B., Hakanen, J. J., Demerouti, E., \& Xanthopoulou, D. (2007). Job resources boost work engagement, particularly when job demands are high. Journal of Educational Psychology, 99(2), 274-284.

Bal, P. M., de Jong, S. B., Jansen, P. G. W., \& Bakker, A. B. (2012). Motivating employees to work beyond retirement: A multi-level study of the role of i-deals and unit climate. Journal of Management Studies, 49(2), 306-331.

Bal, P. M., de Lange, A. H., Jansen, P. G. W., \& van der Velde, M. E. G. (2008). Psychological contract breach and job attitudes: A meta-analysis of age as a moderator. Journal of Vocational Behavior, 72(1), 143-158.

Bal, P. M., \& Jansen, P. G. W. (2015). Idiosyncratic deals for older workers: Increased heterogeneity among older workers enhance the need for I-deals. In P.M. Bal, D. Kooij, \& D.M. Rousseau (eds.), Aging workers and the employee-employer relationship (pp. 129-144). Springer International Publishing. 
Bal, P. M., \& Jansen, P. G. W. (2016). Workplace flexibility across the lifespan. Research in Personnel and Human Resources Management, 34, 43-99.

Bal, P. M., \& Visser, M. S. (2011). When are teachers motivated to work beyond retirement age? The importance of support, change of work role and money. Educational Management Administration \& Leadership, 39(5), 590-602.

Blau, P. M. (1964). Exchange and Power in Social Life. New York: Wiley.

Blundell, R., Dearden, L., Meghir, C., \& Sianesi, B. (1999). Human Capital Investment: The Returns from Education and Training to the Individual, the Firm and the Economy. Fiscal Studies, 20(1), 1-23.

Bowen, D. E., \& Ostroff, C. (2004). Understanding HRM-firm performance linkages: the role of the "strength" of the HRM system. The Academy of Management Review, 29(2), 203-221.

Burmeister, A., \& Deller, J. (2016). Knowledge retention from older and retiring workers: what do we know, and where do we go from here? Work, Aging and Retirement, 2, 87104.

Carter, M. A. T., \& Cook, K. (1995). Adaptation to retirement: role changes and psychological resources. The Career Development Quarterly, 44(1), 67-85.

Chiu, W. C., Chan, A. W., Snape, E., \& Redman, T. (2001). Age stereotypes and discriminatory attitudes towards older workers: An East-West comparison. Human Relations, 54(5), 629-661.

Demerouti, E., Mostert, K., \& Bakker, A. B. (2010). Burnout and work engagement: a thorough investigation of the independency of both constructs. Journal of Occupational Health Psychology, 15(3), 209-222.

Eisenberger, R., Huntington, R., Hutchison, S., \& Sowa, D. (1986). Perceived organizational support. Journal of Applied Psychology, 71(3), 500-507. 
European Commission (2011). White paper: An Agenda for Adequate, Safe and Sustainable Pensions. Brussels: Publication Office of the European Union.

European Commission (2014). Population Ageing in Europe. Facts, Implications and Policy. Luxembourg: Publications Office of the European Union.

Eurostat (2007). The transition of woman and men from work to retirement. Eurostat.

Fasbender, U., Wang, M., Voltmer, J. B., \& Deller, J. (2015). The meaning of work for postretirement employment decisions. Work, Aging and Retirement, 2, 12-23.

Frazis, H., Gittleman, M., \& Joyce, M. (2000). Correlates of training: an analysis using both employer and employee characteristics. Industrial and Labor Relations Review, 53(3), 443-462.

Furunes, T., Mykletun, R. J., Solem, P. E., de Lange, A. H., Syse, A., Schaufeli, W. B., \& Ilmarinen, J. (2015). Late career decision-making: A qualitative panel study. Work, Aging and Retirement, 1(3), 284-295.

Gobeski, K. T., \& Beehr, T. A. (2009). How retirees work: predictors of different types of bridge employment. Journal of Organizational Behavior, 30(3), 401-425.

González-Romá, V., Fortes-Ferreira, L., \& Peiró, J. M. (2009). Team climate, climate strength and team performance. A longitudinal study. Journal of Occupational and Organizational Psychology, 82(3), 511-536.

González-Romá, V., Schaufeli, W. B., Bakker, A. B., \& Lloret, S. (2006). Burnout and work engagement: Independent factors or opposite poles? Journal of Vocational Behavior, 68(1), 165-174.

Guest, D. E., \& Conway, N. (2002). Communicating the psychological contract: an employer perspective. Human Resource Management Journal, 12(2), 22-38. 
Kalokerinos, E. K., von Hippel, C., \& Henry, J. D. (2015). Job attitudes are differentially associated with bridge employment and phased retirement among older Australian employees. Work, Aging and Retirement, 1(2), 190-201.

Kim, S., \& Feldman, D. C. (2000). Working in retirement: the antecedents of bridge employment and its consequences for quality of life in retirement. The Academy of Management Journal, 43(6), 1195-1210.

Kooij, T. A. M. (2010). Motivating older workers: A Lifespan Perspective on the Role of Perceived HR Practices.: VU University Amsterdam: Unpublished doctoral dissertation.

Kooij, D., de Lange, A., Jansen, P., \& Dikkers, J. (2008). Older workers motivation to continue to work: five meanings of age: A conceptual review. Journal of Managerial Psychology, 24(4), 364-394.

Kooij, D. T., Guest, D. E., Clinton, M., Knight, T., Jansen, P. G., \& Dikkers, J. S. (2013). How the impact of HR practices on employee well-being and performance changes with age. Human Resource Management Journal, 23(1), 18-35.

Kooij, D. T., Jansen, P. G., Dikkers, J. S., \& de Lange, A. H. (2014). Managing aging workers: A mixed methods study on bundles of HR practices for aging workers. The International Journal of Human Resource Management, 25(15), 2192-2212.

Kozlowski, S. W., \& Doherty, M. L. (1989). Integration of climate and leadership: Examination of a neglected issue. Journal of Applied Psychology, 74(4), 546-553.

Lund, T., Iversen, L., \& Poulsen, K. B. (2001). Work environment factors, health, lifestyle and marital status as predictors of job change and early retirement in physically heavy occupations. American Journal of Industrial Medicine, 40(2), 161-169.

Lusardi, A., \& Mitchell, O. S. (2009). How ordinary consumers make complex economic decisions: Financial literacy and retirement readiness (No. w15350). National Bureau of Economic Research. 
Maurer, T. J., \& Rafuse, N. E. (2001). Learning, not litigating: managing employee development and avoiding claims of age discrimination. The Academy of Management Executive 15(4), 110-121.

Meyer, J. P., \& Smith, C. A. (2000). HRM practices and organizational commitment: test of a mediation model. Canadian Journal of Administrative Sciences, 17(4), 319-331.

Moen, P., Kojola, E., Kelly, E. L., \& Karakaya, Y. (2016). Men and women expecting to work longer: do changing work conditions matter? Work, Aging and Retirement, 2, 321344.

Muthén, L. K., \& Muthén, B. O. (2012). Mplus: Statistical analysis with latent variables: User's guide. Los Angeles: Muthén \& Muthén.

Ostroff, C., \& Bowen, D. (2000). Moving HR to a higher level: HR practices and organizational effectiveness. In K. Klein \& S. J. Kozlowski (Eds.), Multilevel theory research and methods in organizations Foundations extension and new directions (pp.211-266): Jossey-Bass.

Paauwe, J. (2009). HRM and Performance: achievements, methodological issues and prospects. Journal of Management Studies, 46(1), 129-142.

Pleau, R. L. (2010). Gender Differences in Postretirement Employment. Research on Aging, 32(3), 267-303. doi: 10.1177/0164027509357706

Podsakoff, P. M., MacKenzie, S. B., Lee, J.-Y., \& Podsakoff, N. P. (2003). Common method biases in behavioral research: A critical review of the literature and recommended remedies. Journal of Applied Psychology, 88(5), 879-903.

Robinson, S. L., \& Wolfe Morrison, E. (2000). The development of psychological contract breach and violation: a longitudinal study. Journal of Organizational Behavior, 21(5), 525-546. 
Rousseau, D. M. (1995). Psychological contracts in organizations. Understanding Written and Unwritten Agreements: Thousand Oaks, CA: Sage Publications Inc.

Schaufeli, W., \& Bakker, A. (2003). UWES Utrecht Work Engagement Scale. NL: Occupational Health Psychology Unit. Utrecht.

Schaufeli, W. B., \& Bakker, A. B. (2004). Job demands, job resources, and their relationship with burnout and engagement: a multi-sample study. Journal of Organizational Behavior, 25(3), 293-315.

Schopman, L. M., Kalshoven, K., \& Boon, C. (2015). When health care workers perceive high-commitment HRM will they be motivated to continue working in health care? It may depend on their supervisor and intrinsic motivation. The International Journal of Human Resource Management, in press.

Shultz, K. S., Morton, K. R., \& Weckerle, J. R. (1998). The influence of push and pull factors on voluntary and involuntary early retirees retirement decision and adjustment. Journal of Vocational Behavior, 53, 45-57.

Statistics Netherlands (2012). Statline. Retrieved 06 June 2016, from http://statline.cbs.nl/StatWeb/publication/?VW=T\&DM=SLNL\&PA=80396NED\&D1=1 ,9\&D2=a\&D3=0-3\&D4=0\&D5=1-2\&D6=0-1,3-6,9-12,14,1721\&D7=0\&D8=a\&HD= 100325-1211\&HDR=T,G7,G3,G4\&STB=G1,G2,G5,G6.

Talaga, J. A., \& Beehr, T. A. (1995). Are there gender differences in predicting retirement decisions. Journal of Applied Gerontology, 80(1), 16-28.

Taylor, M. A., \& Shore, L. M. (1995). Predictors of planned retirement age: an application of Beehr's Model. Psychology and Aging, 10(1), 76-83.

Taylor, P., \& Walker, A. (1998). Policies and practices towards older workers: a framework for comparative research. Human Resource Management Journal, 8(3), 61-76. 
U.S. Census Bureau (2016). An Aging World: 2015. International Populations Report. Washington, DC: U.S. Census Bureau.

Van Dalen, H. P., Henkens, K., \& Schippers, J. (2009). Dealing with older workers in Europe: a comparative survey of employers' attitudes and actions. Journal of European Social Policy, 19(1), 47-60.

Van Dalen, H. P., Henkens, K., \& Wang, M. (2015). Recharging or retiring older workers? Uncovering the age-based strategies of European employers. The Gerontologist, 55(5), 814-824.

Wang, M., \& Shultz, K. S. (2010). Employee retirement: A review and recommendations for future investigation. Journal of Management, 36(1), 172-206.

Wang, M., Zhan, Y., Lui, S., \& Shultz, K. S. (2008). Antecedents of bridge employment: a longitudinal investigation. Journal of Applied Psychology, 93, 818-830.

Weckerle, J. R., \& Shultz, K. S. (1999). Influences on the bridge employment decision among older USA workers. Journal of Occupational and Organizational Psychology, 72(3), 317-329.

Zhao, H. A. O., Wayne, S. J., Glibkowski, B. C., \& Bravo, J. (2007). The impact of psychological contract breach on work-related outcomes: a meta-analysis Personnel Psychology, 60(3), 647-680. 
Table 1: Results of Scale Analyses using Confirmatory Factor Analysis

\begin{tabular}{|c|c|c|c|c|c|c|c|c|}
\hline Model & $\chi^{2}$ & $d f$ & $\Delta \chi^{2}$ & $\Delta d f$ & RMSEA & NNFI & GFI & CFI \\
\hline Sample 1 & $(N=313)$ & & & & & & & \\
\hline 6-factor & $480.18 * * *$ & 365 & Baseline model & & .032 & .99 & .99 & .91 \\
\hline 5a-factor & $960.44 * * *$ & 370 & $48.26 * * *$ & 5 & .072 & .95 & .83 & .95 \\
\hline $5 b$-factor & $1622.50 * * *$ & 429 & $1142.32 * * *$ & 64 & .094 & .91 & .75 & .92 \\
\hline 1-factor & $4382.80 * * *$ & 380 & $3902.62 * * *$ & 15 & .180 & .69 & .52 & .73 \\
\hline 7-factor & $642.23 * * *$ & 424 & $162.05^{* * *}$ & 59 & .041 & .98 & .89 & .98 \\
\hline Sample 2 & $(N=352)$ & & & & & & & \\
\hline 6-factor & $557.64 * * *$ & 365 & Baseline model & & .039 & .98 & .90 & .98 \\
\hline 5a-factor & $1011.56 * * *$ & 370 & $453.92 * * *$ & 5 & .070 & .94 & .84 & .95 \\
\hline $5 b$-factor & $1490.30 * * *$ & 429 & $932.66 * * *$ & 64 & .084 & .92 & .79 & .93 \\
\hline 1-factor & $4341.97 * * *$ & 380 & $3784.33 * * *$ & 15 & .170 & .61 & .55 & .66 \\
\hline 7-factor & $703.76 * * *$ & 424 & $146.12 * * *$ & 59 & .043 & .97 & .89 & .98 \\
\hline
\end{tabular}

Note.6-factor model: development HR practices, organizational development climate for older workers, psychological contract fulfillment, organizational commitment, work engagement, motivation to continue working.

5a-factor model: development HR practices, organizational development climate for older workers, psychological contract fulfillment, positive work-attitudes (organizational commitment. work engagement), motivation to continue working.

5b-factor model: development HR practices, psychological contract (organizational development climate for older workers, psychological contract fulfillment), organizational commitment, work engagement, motivation to continue working. 1-factor model: All items loading onto one factor.

7-factor model: development HR practices, organizational development climate for older workers, psychological contract fulfillment, organizational commitment, work engagement, motivation to continue working, with all items loading onto one common method factor 
Table 2: Means, Standard Deviations, and Correlations among the variables of Sample 1.

\begin{tabular}{|c|c|c|c|c|c|c|c|c|c|c|c|c|c|c|c|c|c|}
\hline & & $\mathrm{M}$ & SD & 1 & 2 & 3 & 4 & 5 & 6 & 7 & 8 & 9 & 10 & 11 & 12 & 13 & 14 \\
\hline 1 & Age & 49.78 & 5.63 & -- & & & & & & & & & & & & & \\
\hline 2 & Gender & 1.91 & -- & -.02 & -- & & & & & & & & & & & & \\
\hline 3 & Subjective Health & 3.08 & .56 & -.03 & -.05 & -- & & & & & & & & & & & \\
\hline 4 & Education & 3.34 & 1.66 & -.06 & $-.34 * *$ & .02 & -- & & & & & & & & & & \\
\hline 5 & Sector Experience & 3.62 & .74 & .10 & .01 & -.01 & $.16^{* *}$ & -- & & & & & & & & & \\
\hline 6 & Training Participation & 1.49 & .50 & -.11 & -.06 & .03 & $.20 * *$ & $.14^{*}$ & -- & & & & & & & & \\
\hline 7 & Financial Importance & 3.65 & 1.19 & -.10 & .03 & -.04 & -.09 & $-.13^{*}$ & -.09 & -- & & & & & & & \\
\hline 8 & Expectations Partner & 3.86 & 1.19 & $-.13^{*}$ & .05 & -.05 & .10 & -.05 & .08 & $.21 * *$ & -- & & & & & & \\
\hline 9 & Development HR & 2.66 & 1.06 & $-.18 * *$ & -.05 & .09 & $.14 *$ & -.07 & $.27 * *$ & .03 & $.19 * *$ & -- & & & & & \\
\hline 10 & Development Climate & 2.96 & .65 & $-.17 * *$ & .01 & $.13^{*}$ & .04 & $-.16^{* *}$ & .06 & .02 & .08 & $.52 * *$ & -- & & & & \\
\hline 11 & PC Fulfillment & 362 & .88 & .06 & -.04 & .06 & .03 & $-.14 *$ & .01 & .08 & .11 & $.38 * *$ & $.28 * *$ & -- & & & \\
\hline 12 & Organizational Commitment & 3.20 & .75 & $.15^{* *}$ & -.06 & .05 & .04 & -.07 & -.02 & .11 & -.01 & $.27 * *$ & $.27 * *$ & $.42 * *$ & -- & & \\
\hline 13 & Work Engagement & 5.73 & 1.02 & -.03 & .04 & .10 & .01 & -.09 & .06 & .04 & .05 & $.28 * *$ & $.25^{* *}$ & $.30 * *$ & $.40 * *$ & -- & \\
\hline 14 & Motivation to Continue Working & 2.62 & 1.01 & .10 & $-.17 * *$ & .07 & .08 & -.04 & -.02 & .08 & $-.12 *$ & .06 & $.14^{*}$ & .11 & $.30 * *$ & $.22 * *$ & -- \\
\hline
\end{tabular}

Note. $N=313 ; * p<.05, * * p<.01$. Gender: $1=$ male; $2=$ female. 
Table 3: Means, Standard Deviations, and Correlations among the variables of Sample 2.

\begin{tabular}{|c|c|c|c|c|c|c|c|c|c|c|c|c|c|c|c|c|c|}
\hline & & $\mathrm{M}$ & SD & 1 & 2 & 3 & 4 & 5 & 6 & 7 & 8 & 9 & 10 & 11 & 12 & 13 & 14 \\
\hline 1 & Age & 50.05 & 5.26 & -- & & & & & & & & & & & & & \\
\hline 2 & Gender & 1.88 & -- & -.09 & -- & & & & & & & & & & & & \\
\hline 3 & Subjective Health & 3.12 & .51 & .07 & -.03 & -- & & & & & & & & & & & \\
\hline 4 & Education & 3.59 & 1.61 & -.05 & $-.36 * *$ & -.06 & -- & & & & & & & & & & \\
\hline 5 & Sector Experience & 1.52 & .71 & $.12 *$ & $-.16^{* *}$ & -.01 & $.22 * *$ & -- & & & & & & & & & \\
\hline 6 & Training Participation & 3.68 & .50 & -.09 & $-.12 *$ & .02 & $.17 * *$ & $.17 * *$ & -- & & & & & & & & \\
\hline 7 & Financial Importance & 3.95 & 1.13 & $-.22 * *$ & -.10 & .05 & $-.14 * *$ & -.03 & -.04 & -- & & & & & & & \\
\hline 8 & Expectations Partner & 2.64 & 1.09 & -.01 & .10 & .01 & $-.18 * *$ & -.01 & -.06 & $.23^{* *}$ & -- & & & & & & \\
\hline 9 & Development HR & 3.06 & 1.04 & -.04 & -.09 & -.02 & .10 & -.04 & $.24 * *$ & .10 & -.03 & -- & & & & & \\
\hline 10 & Development Climate & 3.82 & .64 & -.06 & $-.16^{* *}$ & -.05 & .09 & -.07 & $.14 * *$ & .01 & $-.15 * *$ & $.49 * *$ & -- & & & & \\
\hline 11 & PC Fulfillment & 3.44 & .82 & -.04 & $-.13 *$ & .06 & .11 & -.08 & $.12^{*}$ & .10 & .04 & $.43 * *$ & $.34 * *$ & -- & & & \\
\hline 12 & Organizational Commitment & & .66 & $.11 *$ & $-.15 * *$ & -.01 & .01 & .04 & -.05 & $.13^{*}$ & .06 & $.32 * *$ & $.34 * *$ & $.30 * *$ & -- & & \\
\hline 13 & Work Engagement & 5.82 & .94 & .07 & .03 & .08 & -.05 & -.08 & .01 & .03 & $.11^{*}$ & $.24 * *$ & $.20 * *$ & $.18 * *$ & $.31 * *$ & -- & \\
\hline 14 & Motivation to Continue Working & 2.72 & 1.06 & .07 & -.01 & $.15^{* *}$ & .01 & -.06 & -.03 & .07 & $-.13 *$ & .01 & .09 & .03 & $.15^{* *}$ & $.16^{* *}$ & -- \\
\hline
\end{tabular}

Note. $N=352 . * p<.05, * * p<.01$. Gender: $1=$ male; $2=$ female. 
Table 4: Unstandardized Coefficients of SEM-analyses for Sample 1.

\begin{tabular}{|c|c|c|c|c|c|}
\hline & $\begin{array}{l}\text { Perceived } \\
\text { Development } \\
\text { Climate }\end{array}$ & $\begin{array}{l}\text { Psychological } \\
\text { Contract } \\
\text { Fulfillment }\end{array}$ & $\begin{array}{l}\text { Affective } \\
\text { Commitment }\end{array}$ & $\begin{array}{l}\text { Work } \\
\text { Engagement }\end{array}$ & $\begin{array}{l}\text { Motivation to } \\
\text { Continue } \\
\text { Working }\end{array}$ \\
\hline Age & $-.013 *$ & $.018^{*}$ & $.021 * *$ & .001 & $.017 *$ \\
\hline Gender & -.125 & -.154 & .026 & -.034 & $-.269 *$ \\
\hline Subjective Health & -.012 & -.092 & -.029 & -.012 & -.018 \\
\hline Education & .013 & -.004 & .037 & -.005 & .048 \\
\hline Sector Experience & -.020 & -.034 & -.048 & .030 & -.052 \\
\hline Training Participation & -.078 & -.069 & .018 & .025 & .050 \\
\hline Financial Importance & -.014 & -.015 & .038 & .033 & .036 \\
\hline Expectations Partner & .002 & $.082 *$ & -.028 & .049 & $-.100 *$ \\
\hline Development HR & $.386 * * *$ & $.402 * * *$ & & & \\
\hline Development Climate & & & $.198 * *$ & $.311 * *$ & \\
\hline PC Fulfillment & & & $.296 * * *$ & $.225 * *$ & \\
\hline Commitment & & & & & $.283 * *$ \\
\hline Engagement & & & & & $.153 *$ \\
\hline
\end{tabular}

Note. $\mathrm{N}=313 . * \mathrm{p}<.05, * * \mathrm{p}<.01, * * * \mathrm{p}<.001$. Gender: $1=$ male $; 2=$ female.

Table 5: Unstandardized Coefficients of SEM-analyses for Sample 2.

\begin{tabular}{|c|c|c|c|c|c|}
\hline & $\begin{array}{l}\text { Perceived } \\
\text { Development } \\
\text { Climate }\end{array}$ & $\begin{array}{l}\text { Psychological } \\
\text { Contract } \\
\text { Fulfillment }\end{array}$ & $\begin{array}{l}\text { Affective } \\
\text { Commitment }\end{array}$ & $\begin{array}{l}\text { Work } \\
\text { Engagement }\end{array}$ & $\begin{array}{l}\text { Motivation to } \\
\text { Continue } \\
\text { Working }\end{array}$ \\
\hline Age & -.01 & .008 & $.018 * *$ & .009 & .016 \\
\hline Gender & $-.208 * *$ & -.086 & .074 & -.017 & .084 \\
\hline Subjective Health & .031 & .090 & .0244 & .016 & .117 \\
\hline Education & -.014 & .028 & .012 & -.005 & .036 \\
\hline Sector Experience & .037 & -.044 & -.002 & .010 & -.085 \\
\hline Training Participation & -.024 & .000 & $-.087 *$ & -.073 & -.028 \\
\hline Financial Importance & -.007 & .058 & .041 & -.036 & .093 \\
\hline Expectations Partner & $-.104 * *$ & .041 & .039 & .090 & -.096 \\
\hline Development HR & $.438 * * *$ & $.385^{* * *}$ & & & \\
\hline Development Climate & & & $.208 * * *$ & $.316^{* *}$ & \\
\hline PC Fulfillment & & & $.122 *$ & $.176^{*}$ & \\
\hline Commitment & & & & & .243 \\
\hline Engagement & & & & & $.152 *$ \\
\hline
\end{tabular}

Note. $\mathrm{N}=352 . * \mathrm{p}<.05, * * \mathrm{p}<.01, * * * \mathrm{p}<.001$. Gender: $1=$ male $; 2=$ female. 
Figure 1: Research Model of the Current Study

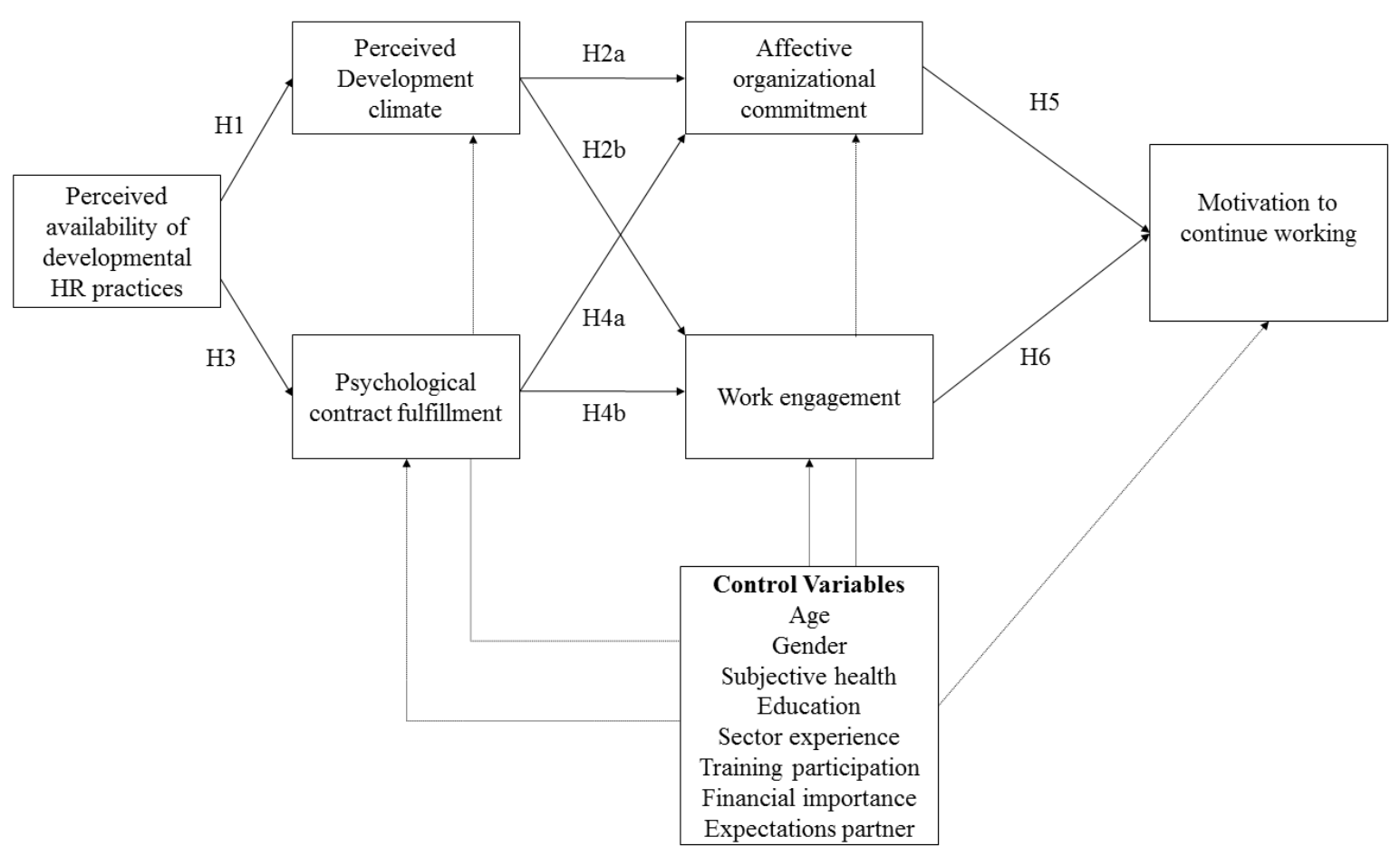


Appendix A: Items used in the current study

\begin{tabular}{l} 
Measures \\
\hline Perceived Availability of Developmental HR Practices (Kooij et al., 2014)
\end{tabular}

To what extent does your organization offer you the following practices?

- Career planning

- Development on job

- Promotion

- Regular Training

Perceived Development Climate (Kooij, 2010)

In our organization, older workers are developed and are encouraged to learn new things.

Our organization uses the existing experience, knowledge, and capacities of older workers.

In our organization, older workers are encouraged to maintain and polish their skills.

My supervisor encourages older workers to develop and to learn new things.

My supervisor uses the existing experience, knowledge, and capacities of older workers.

My supervisor encourages older workers to maintain and polish their skills.

Psychological Contract Fulfillment (Robinson \& Morrison, 2000)

Almost all the promises made by my organization during recruitment have been kept so far.

I feel that my organization has come through in fulfilling the promises made to me when I was hired.

So far my organization has done an excellent job of fulfilling its promises to me.

I have not received everything promised to me in exchange for my

contributions. (R)

My organization has broken many of its promises to me even though I've

upheld my side of the deal. (R)

Affective Commitment (Allen \& Meyer, 1990)

I would be very happy to spend the rest of my career with this organization.

I enjoy discussing my organization with people outside it.

I really feel as if this organization's problems are my own.

I think that I could easily become as attached to another organization as I am

to this one $(\mathrm{R})$.

I do not feel like 'part of the family' at my organization (R).

I do not feel 'emotionally attached' to this organization (R).

This organization has a great deal of personal meaning for me.

I do not feel a strong sense of belonging to my organization (R).

Work Engagement (Schaufeli \& Bakker, 2003)

At my work, I feel bursting with energy.

At my job, I feel strong and vigorous.

I am enthusiastic about my job.

My job inspires me.

When I get up in the morning, I feel like going to work.

I am proud on the work that I do.

Motivation to Continue Working (Armstrong-Stassen \& Schlosser, 2008)
Response Scales

$1=$ not at all; $5=$ to $\mathrm{a}$ very great extent

$1=$ not at all; $5=$ to a very great extent
$1=$ not at all; $5=$ to $a$ very great extent
$1=$ not at all; $5=$ to a very great extent 
Barring unforeseen circumstances, I would remain working as long as possible.

If I were completely free to choose, I would prefer to continue working after my flex-pension age.

I expect to continue working as long as possible after my flex-pension age.

I am highly motivated to continue working after my flex-pension age.
$1=$ totally disagree; 5

totally agree 